\title{
ELECTROCHEMISTRY OF LB FILMS OF MIXED MGDG:UQ ON ITO
}

\author{
Javier Hoyo ${ }^{1}$, Ester Guaus ${ }^{1, *}$, Juan Torrent-Burgués ${ }^{1,2}$, F Sanz ${ }^{2,3}$ \\ ${ }^{1}$ Universitat Politècnica de Catalunya, Dpt. Chemical Engineering, 08222 Terrassa \\ (Barcelona), Spain \\ ${ }^{2}$ Institut de Bioenginyeria de Catalunya (IBEC), 08028 Barcelona, Spain \\ ${ }^{3}$ Universitat de Barcelona, Dpt. Physical-Chemistry, 08028 Barcelona, Spain. \\ *Corresponding author: ester.guaus@upc.edu. C/ Colom 1, 08222 Terrassa \\ (Barcelona), Spain. TI: 34937398043.
}

\begin{abstract}
The electrochemical behaviour of biomimetic monolayers of monogalactosyldiacylglycerol (MGDG) incorporating ubiquinone-10 (UQ) has been investigated. MGDG is the principal component in the thylakoid membrane and UQ seems a good substitute for plastoquinone-9, involved in photosynthesis chain. The monolayers have been performed using the Langmuir and Langmuir-Blodgett (LB) techniques and the redox behaviour of the LB films, transferred at several surface pressures on a glass covered with indium-tin oxide (ITO), has been characterized by cyclic voltammetry. The cyclic voltammograms show that UQ molecules present two redox processes (I and II) at high UQ content and high surface pressures, and only one redox process (I) at low UQ content and low surface pressures. The apparent rate constants calculated for processes I and II indicate a different kinetic control for the reduction and the oxidation of $\mathrm{UQ} / \mathrm{UQH}_{2}$ redox couple, being $\mathrm{k}_{\mathrm{Rapp}}(\mathrm{I})=2.2 \cdot 10^{-5} \mathrm{~s}^{-1}$, $\mathrm{k}_{\text {Rapp }}(\mathrm{II})=5.1 \cdot 10^{-14} \mathrm{k}_{\text {Oapp }}(\mathrm{I})=3.3 \cdot 10^{-3} \mathrm{~s}^{-1}$ and $\mathrm{k}_{\mathrm{Oapp}}(\mathrm{II})=6.1 \cdot 10^{-6} \mathrm{~s}^{-1}$, respectively. The correlation of the redox response with the physical states of the LB films allows determining the positions of the UQ molecules in the biomimetic monolayer, which change with the surface pressure and the UQ content. These positons are known as diving and swimming.
\end{abstract}

\section{Keywords}

Ubiquinone, Monogalactosyldiacylglycerol, Langmuir-Blodgett film, Cyclic voltammetry, Modified ITO electrode, Electron transfer 


\section{Introduction}

Electron transfer processes occurs in biological membranes such as thylakoid membranes of chloroplasts or mitochondrial membranes. The understanding of these processes is important for mimicking natural membranes and processes for applications in bioenergetics or bioremediation. Monogalactosyldiacylglycerol, MGDG, is the principal lipid component of thylakoid membranes (ca. 50\%) versus dipalmytoilphosphatidylchloline, DPPC, which is present in mitochondrial membranes. On the other hand, quinones are redox molecules that act as electron and proton shuttles in natural electron transfer processes. Ubiquinones, UQs, especially UQ-10, are involved in the respiratory chain whereas plastoquinones, PQs, especially PQ-9, are involved in the photosynthetic chain $[1,2]$. Some attempts have been done to simulate artificial photosynthesis using others quinones than PQ-9 [3-5], being UQ-10 one natural candidate because it is structurally close to PQ-9 and its obtaining cost is quite lower. In the following, for simplicity, UQ-10 will be indicated as UQ and PQ-9 as $P Q$.

For the study of quinone incorporation in biomimetic membranes, both the monolayer formation and the unilamellar vesicle formation [6] approaches can be used. One of the first attempts to study the electrochemistry of UQ used lipid monolayer and bilayer systems supported on $\mathrm{Hg}$ [7-10]. On solid electrodes, different methods have been applied to modify the surface of the electrode with a thin layer simulating the structure of the lipid layer [11], where the quinone molecules can be embedded. The Langmuir-Blodgett (LB), the Langmuir-Schaefer (LS) and the vesicle fusion methods have been the most often applied to prepare supported lipid bilayers [12-18]. Bilayers so obtained have been used to study the electron transport properties of UQ [19-21] by voltammetry. On the other hand, the Langmuir and LB monolayer formation [22] has also been used. Other techniques like cast coating [23, 24], black lipid membrane (BLM) [25], and other thin layer approaches [26-29] have also been used to study the voltammetric behaviour of UQ and other quinone derivatives.

The behaviour of ubiquinone monolayers, and mixed ubiquinone-phospholipid monolayers were investigated previously by Quinn et al. [30] by obtaining the surface pressure-area isotherms of the Langmuir films. This former study reported that the characteristics of the mixed monolayers depend markedly on the surface pressure of the monolayer. One relevant factor such as the location of the ubiquinone molecules in the membrane during the redox process is still unclear. The electron and proton transfers involving the quinone moiety depend on the availability of water molecules for the redox centre whereas a lipid environment should be available for the tail. The Langmuir technique offers a unique way to control these factors through the lipid film formation and compression.

In this work the electrochemistry of mixed films of MGDG and UQ on ITO has been studied, being the thermodynamic and topographic results of these films presented in a previous article [31]. MGDG has been chosen because it is the principal component in the thylakoid membrane and UQ seems a good substitute for $P Q$. The molar ratios MGDG:UQ 5:1 and 10:1 used are a bit higher but not too far from the biological ones, providing enough UQ concentration for a good analysis and for observing the influence of the lateral pressure on the UQ insertion in the MGDG matrix. In order to study the influence of the UQ in the MGDG film at different surface pressures, the Langmuir and LB techniques have been used that will allow us to investigate the influence of this parameter on the UQ location. The redox behaviour of the LB films has been characterized by cyclic voltammetry (CV) using a glass covered with indium-tin oxide (ITO) as working electrode. ITO has good optical and electrical properties, being these 
properties suitable for solar cells and artificial photosynthesis applications. Finally, we try to correlate the film formation and film structure with the redox response. The electrochemistry response obtained with the ITO-MGDG:UQ system will be compared with that obtained by the authors in the ITO-UQ and ITO-DPPC:UQ systems [21,22].

\section{Experimental}

\subsection{Materials}

Saturated monogalactosyldiacylglycerol (MGDG), with acyl=stearoyl (18:0), was purchased from Matreya (USA) and ubiquinone-10 (UQ) HPLC grade was from SigmaAldrich. $\mathrm{KH}_{2} \mathrm{PO}_{4}, \mathrm{KCl}$ and chloroform of analytical grade were used in solutions preparation. Water was ultrapure MilliQ ${ }^{\circledR}(18.2 \mathrm{M} \Omega \cdot \mathrm{cm})$. Indium tin oxide deposited glass slides (ITO) were purchased to SOLEMS (France) and mica sheets to TED PELLA Inc (CA). Pure components solutions $(1 \mathrm{mg} / \mathrm{mL})$ were prepared dissolving MGDG and UQ in chloroform in separate glass vials. MGDG and UQ were completely dissolved after three hours. Mixtures were prepared mixing the appropriated volume of each pure component solutions to achieve the desired MGDG:UQ ratio.

\subsection{Monolayer formation}

Langmuir and Langmuir-Blodgett (LB) monolayer formation were carried on a Nima model 1232D1D2 trough using MilliQ ${ }^{\circledR}$ quality water as subphase. LB monolayers were transferred to ITO at defined surface pressure values $(\pi)$. Monolayer formation was carried out adding the solution to the subphase and waiting 15 minutes for perfect spreading. Barrier closing rate was fixed at $25 \mathrm{~cm}^{2} \cdot \mathrm{min}^{-1}\left(5.9 \AA^{2} \cdot \mathrm{molec}^{-1} \cdot \mathrm{min}^{-}\right.$ $\left.{ }^{1}\right)$. LB film transfer was conducted dipping the substrate (ITO slide) on the subphase before adding the solution and five minutes were lagged after pressure setpoint was achieved. Transfer speed was set at $5 \mathrm{~mm} / \mathrm{min}$ linear velocity. Experiments were conducted at $21 \pm 1^{\circ} \mathrm{C}$.

\subsection{Electrochemical characterization}

The voltammetric measurements were performed in a conventional threeelectrode cell using an Autolab Potentiostat-Galvanostat PGSTAT-12 (Ecochemie, NL). Working electrodes used were ITO slides $(10 \mathrm{~mm} \times 25 \mathrm{~mm})$ cleaned once with ethanol and three times with MilliQ ${ }^{\circledR}$ grade water. Counter electrode was a platinum wire in spiral geometry and the reference electrode was an $\mathrm{Ag} / \mathrm{AgCl} / 3 \mathrm{M} \mathrm{KCl}$ microelectrode model DRIREF-2SH from WPI (World Precision Instruments). This reference electrode was mounted in a Lugging capillary containing $\mathrm{KCl}$ solution at the same cell concentration. All reported potentials were referred to this electrode. The electrochemical cell contained $0.150 \mathrm{M} \mathrm{KCl}$ as supporting electrolyte at $\mathrm{pH} 7.4$ adjusted with the $\mathrm{KH}_{2} \mathrm{PO}_{4} / \mathrm{K}_{2} \mathrm{HPO}_{4}$ buffer. All solutions were freshly prepared with MilliQ ${ }^{\circledR}$ grade water and de-aerated with flow of Argon gas for 15 minutes prior the CV experiments, which were conducted at $21 \pm 1^{\circ} \mathrm{C}$. Voltammetric experiments were carried out at different scan rates, scanning towards negative potentials in a home-made glass cell with a reaction area of $33 \mathrm{~mm}^{2}$. 


\section{Results}

\subsection{LB film formation}

The main results about the surface pressure-area, $\pi-A$, isotherms and thermodynamic processing of mixed films of MGDG and UQ have been presented previously [31]. Table 1 summarizes some of the characteristic values of these isotherms. One of the principal obtained results is that the presence of UQ affects the MGDG isotherm shape especially at low surface pressures and, on the other hand, the mixed films present a main UQ expulsion from the MGDG matrix after a certain surface pressure is achieved (see Table 1). The UQ presence affects the physical states (liquid expanded, LE, liquid condensed, LC, and solid, S) of the monolayers (Fig. 1), producing less ordered states in respect to pure MGDG.

Table 1. Values of collapse surface pressure $\left(\pi_{c}\right)$, area of lift-off $\left(A_{l_{0}}\right)$, surface pressure at the main UQ expulsion ( $\left.\pi_{\mathrm{mUQ}}\right)$, area at the main UQ expulsion $\left(\mathrm{A}_{\mathrm{mUQe}}\right)$, maximum value of the inverse of compressibility before physical state change $\left(C_{s}^{-1} \max b\right)$, maximum value of the inverse of compressibility after physical state change $\left(C_{s}^{-1} \max a\right)$, and monolayer physical state (PS).

Figure 1. Surface pressure-area isotherms and inverse of the compressibility modulus vs. surface pressure (inset) for the films: (A) MGDG, (B) MGDG:UQ 10:1, (C) MGDG:UQ 5:1 and (D) UQ.

\subsection{Electrochemistry characterization on ITO electrode}

\subsubsection{ITO-MGDG/electrolyte system}

Fig. 2 shows the cyclic voltammogram at a scan rate, $v$, of $10 \mathrm{mV} \cdot \mathrm{s}^{-1}$ of LB films of MGDG transferred on ITO in a $0.150 \mathrm{M} \mathrm{KCl}$ cell solution buffered at $\mathrm{pH} 7.4$. The LB films have been transferred at two different surface pressures selected according to the criterion of being one surface pressure predominated by the LC state and other surface pressure predominated by the $S$ state (Fig. 1). Moreover, the surface pressure $\pi=33$ $\mathrm{mN} \cdot \mathrm{m}^{-1}$ has been selected because it is close to the lateral pressure in biological membranes [32]. Previously, the ITO/electrolyte system has been studied and it shows that ITO behaves as a polarizable electrode in the experimental conditions (see dashed line in Fig. 2). In our experiments, three CVs are required to obtain the stationary state in the electrochemical response, presenting a good reproducibility from the third scan and until at least 15 cycles. The voltammograms indicate that in the potential range between 0.80 and $-0.40 \mathrm{~V}$ the ITO-MGDG electrode does not show faradaic responses and that the effect of the applied electrical potential on the lipid monolayer is low. At more cathodic potentials than $-0.40 \mathrm{~V}$ a continuous increase (not shown) of the intensity was obtained, indicating that hydrogen evolution becomes important, in accordance with the behaviour reported for the ITO-DPPC electrode [21, 22]. Studies 
of the effect of electrical potential on lipid supported monolayers and bilayers $[15,33$, 34] show that, imposing a progressively more negative potential at the electrode surface, the lipid layer becomes less ordered, making easier the entrapment and diffusion of proton ions from an electrolyte solution.

Figure 2. Cyclic voltammograms at $v=10 \mathrm{mV} \cdot \mathrm{s}^{-1}$ of the systems: (A) ITO/electrolyte, (B) ITO-MGDG/electrolyte at $\pi=33 \mathrm{mN} \cdot \mathrm{m}^{-1}$ and (C) ITO-MGDG/electrolyte at $\pi=6$ $\mathrm{mN} \cdot \mathrm{m}^{-1}$. All CVs have been performed in a $0.150 \mathrm{M} \mathrm{KCl}$ solution buffered at $\mathrm{pH} 7.4$. Inset: $C_{d}$ of the $(A)$ and $(B)$ systems obtained from the CVs.

The cyclic voltammogram of the ITO-MGDG/electrolyte system has been used to evaluate its $C_{d}$ (Inset of Fig. 2) from the values of voltammetric charging current [22]. The ITO-MGDG electrode presents slightly higher $\mathrm{C}_{d}$ value than bare ITO, presenting a nearly constant value $\mathrm{C}_{\mathrm{d}} \approx 4 \mu \mathrm{F} \cdot \mathrm{cm}^{-2}$ in the potential working screen used. $\mathrm{C}_{\mathrm{d}}$ values $\approx$ $1.8 \mu \mathrm{F} \cdot \mathrm{cm}^{-2}$ have been reported for high quality lipid monolayers [35] so indicating that our monolayer is not completely homogeneous and it presents few defects. The fact that the voltammogram presents a cyclic behaviour indicates that the lipid layer is permeable to water molecules, and after the third scan, a stable water content is achieved in the monolayer. This effect, and its reversibility, of the applied potential on lipid LB monolayers on ITO are explained by the lipid heads-ITO affinity [12].

\subsubsection{ITO-MGDG:UQ/electrolyte system}

In this section, the electrochemical behaviour of the ITO-MGDG:UQ/electrolyte systems and its mathematical processing are presented. The results of the pure component UQ and their corresponding discussion were exposed in a previous work [22]. In our experiments, three CVs are required to obtain the stationary state in the electrochemical response, presenting a good reproducibility from the third scan and until at least 15 cycles. Figs. 3 and 4 present the cyclic voltammograms at $10 \mathrm{mV} \cdot \mathrm{s}^{-1}$, and at several surface pressures, of the ITO-MGDG:UQ 5:1 and 10:1 systems, respectively.

Figure 3. Cyclic voltammograms at $v=10 \mathrm{mV} \cdot \mathrm{s}^{-1}$ of the (A) ITO-MGDG LB film transferred at $\pi=33 \mathrm{mN} \cdot \mathrm{m}^{-1}$ and of the (B, C, D) ITO-MGDG:UQ 5:1 LB films transferred at several surface pressures: (B) $\pi=6 \mathrm{mN} \cdot \mathrm{m}^{-1}$, (C) $\pi=15 \mathrm{mN} \cdot \mathrm{m}^{-1}$ and (D) $\pi=33 \mathrm{mN} \cdot \mathrm{m}^{-1}$. Inset: $\mathrm{CV}$ of the system (D) in a shorter potential working screen. All $\mathrm{CVs}$ have been performed in a $0.150 \mathrm{M} \mathrm{KCl}$ solution buffered at $\mathrm{pH} 7.4$.

Figure 4. Cyclic voltammograms at $v=10 \mathrm{mV} \cdot \mathrm{s}^{-1}$ of the (A) ITO-MGDG LB film transferred at $\pi=33 \mathrm{mN} \cdot \mathrm{m}^{-1}$ and of the (B, C, D) ITO-MGDG:UQ 10:1 LB films transferred at several surface pressures: (B) $\pi=6 \mathrm{mN} \cdot \mathrm{m}^{-1},(\mathrm{C}) \pi=15 \mathrm{mN} \cdot \mathrm{m}^{-1}$ and (D) $\pi=33 \mathrm{mN} \cdot \mathrm{m}^{-1}$. All CVs have been performed in a $0.150 \mathrm{M} \mathrm{KCl}$ solution buffered at $\mathrm{pH}$ 7.4 . 
The ITO-MGDG:UQ 5:1 at $\pi=33 \mathrm{mN} \cdot \mathrm{m}^{-1}$ shows two reduction and two oxidation peaks whereas at $\pi=6 \mathrm{mN} \cdot \mathrm{m}^{-1}$ only a reduction and an oxidation peak are present. At $\pi=15 \mathrm{mN} \cdot \mathrm{m}^{-1}$ one wide wave is observed for reduction and two peaks are observed for the oxidation process. On the other hand, the ITO-MGDG:UQ/electrolyte 10:1 presents only one reduction and one oxidation peak at all the surface pressures studied. The redox processes have been labelled according to those observed for the ITO-UQ and ITO-DPPC:UQ systems [22]. The main differences between the DPPC:UQ and the MGDG:UQ systems are, on the one hand, the non-appearance of the reduction peak of process I', located between peaks $I_{R}$ and $I_{R}$, in the later system, although the broadness of the peak of process I may indicate that more than one process are involved. On the other hand, the process lo becomes more important than Ilo in the MGDG:UQ system when increasing the surface pressure.

In order to gain more information about the system, voltammograms at several scan rates have been performed and Fig. 5 shows the CVs of the MGDG:UQ 5:1 and $10: 1$ systems on ITO for $\pi=33 \mathrm{mN} \cdot \mathrm{m}^{-1}$, being both experiments scanned at $200 \mathrm{mV} \cdot \mathrm{s}^{-}$ ${ }^{1}$. In addition, the inset of Fig. 5 represents the $\mathrm{CVs}$ at $10 \mathrm{mV} \cdot \mathrm{s}^{-1}$ of the same systems and also the corresponding to the ITO-UQ system at $\pi=11 \mathrm{mN} \cdot \mathrm{m}^{-1}$. Despite of the increase in the scan rate for the ITO-MGDG:UQ systems, the deconvolution of both processes that seems involved in the cathodic and anodic scan of process $I$ is not possible. In addition, the Fig. 5 confirms that the ITO-MGDG:UQ 10:1 system at $\pi=33$ $\mathrm{mN} \cdot \mathrm{m}^{-1}$ only shows process I although a wider potential working screen has been tested (not shown). In this figure, the scan rate is increased in such way that the hydrogen evolution present in all the voltammograms at all compositions starts at more negative potentials than at $10 \mathrm{mV} \cdot \mathrm{s}^{-1}$, indicating that this evolution is a quite slower process than process II. The peak and formal potentials of processes I and II for the ITO-MGDG:UQ 5:1 and 10:1 systems, at the scan rate of $10 \mathrm{mV} \cdot \mathrm{s}^{-1}$, are summarized in Table 2.

Figure 5. Cyclic voltammograms at $v=200 \mathrm{mV} \cdot \mathrm{s}^{-1}$ of the ITO-MGDG:UQ LB films transferred at $\pi=33 \mathrm{mN} \cdot \mathrm{m}^{-1}$ with different MGDG:UQ content: (A) 10:1 and (B) 5:1. Inset: CVs of the systems (A) and (B) and CV of the (C) ITO-UQ LB film transferred at $\pi=11 \mathrm{mN} \cdot \mathrm{m}^{-1}$, in a shorter potential working screen and scanned at $v=10 \mathrm{mV} \cdot \mathrm{s}^{-1}$. All $\mathrm{CVs}$ have been performed in a $0.150 \mathrm{M} \mathrm{KCl}$ solution buffered at $\mathrm{pH} 7.4$.

Table 2. Redox peaks potentials for processes I and II and the formal potential that they represent for the ITO-MGDG:UQ 5:1 and 10:1 systems.

\section{Discussion}

\subsection{Electrochemical response of the MGDG:UQ-ITO/electrolyte system}

According to the literature $[7,22,36]$, the global electrochemical reaction of the $\mathrm{UQ} / \mathrm{UQH}_{2}$ redox couple proposed for process I and II in our experimental conditions is 
described by eq. (1), which is similar than that of benzoquinone in aqueous buffered solution.

$$
\mathrm{UQ}+2 \mathrm{e}^{-}+2 \mathrm{H}^{+} \rightarrow \mathrm{UQH}_{2}
$$

As it can be seen, the global redox process is $\mathrm{pH}$ dependent. In this work the influence of the $\mathrm{pH}$ has not been studied and, then, only the global reaction will be considered to describe the electrochemical behaviour of the $\mathrm{UQ} / \mathrm{UQH}_{2}$ redox couple. It is also worth to comment that the first ionization constant of $\mathrm{UQH}_{2}$ is $\mathrm{pKa}=12[9,27]$, thus at the $\mathrm{pH} 7.4$ the neutral form of $\mathrm{UQH}_{2}$ is predominant. The current intensity of the redox peaks $\left(I_{\mathrm{p}}\right)$ has been studied for the ITO-MGDG:UQ 5-1 system at several scan rates and it has been shown that the reduction (not shown) and the oxidation peak current are related by a linear dependence with the scan rate (Fig. 6) so indicating that UQ molecules are surface confined in all the processes $[37,38]$ and that the electron transfer process is not diffusion controlled. These observations are also valid for ITOMGDG:UQ 10:1 (not shown). Our results are in line with the observations of Märtensson and Agmo [39] for scan rates $<1 \mathrm{~V} \cdot \mathrm{s}^{-1}$, Gordillo and Schiffrin [9] and Li et al. [40] for monolayers containing UQ confined on the electrode surface.

Figure 6. Oxidation peak current vs. the scan rate for the ITO-MGDG:UQ 5:1 system transferred at several surface pressures. Symbols: $(\boldsymbol{\bullet})$ Process I $\pi=6 \mathrm{mN} \cdot \mathrm{m}^{-1},(\mathbf{\Delta})$

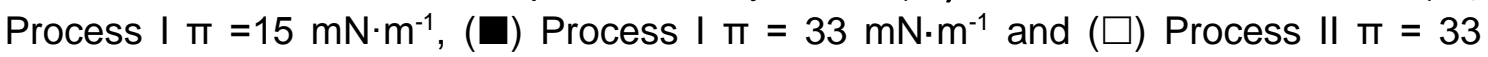
$\mathrm{mN} \cdot \mathrm{m}^{-1}$. (Each data point represents a single scan).

The voltammograms presented in Fig. 3-5, show a non-symmetrical shape, being the reduction peak sharper than the oxidation one. A similar situation was observed by Märtensson and Agmo [39] and Hong and Park [41] studying UQ and hydroquinone respectively and was also observed studying the electrochemical behaviour of the ITO-DPPC:UQ/electrolyte system [21,22]. The different shape of reduction and oxidation peaks can be explained by the different hydrophilic character of the redox couple $U Q / \cup Q H_{2}$. The larger polarity of $\mathrm{UQH}_{2}$ compared with UQ leads the former to establish better attractive interactions by dipole-dipole or hydrogen bond between $\mathrm{UQH}_{2}$ and MGDG headgroups and, in addition, the $\mathrm{UQH}_{2}-\mathrm{ITO}, \mathrm{UQH}_{2}-\mathrm{UQH}_{2}$ and $\mathrm{UQH}_{2}$-water interactions are also enhanced $\left.[2,30,39,42]\right)$. During the oxidation scan $\mathrm{UQH}_{2}$ is the reactant so the possibilities of hydrogen bonds are larger, increasing the stabilization of the $\mathrm{UQH}_{2}$ molecule and making it more difficult to oxidise. These arguments are also valid for explaining the larger width of the oxidation peak compared with that of the reduction process.

The separation of redox peaks for process I or process II in the voltammograms presented in Fig. 3-5 is large, even at low scan rates, indicating an irreversible redox behaviour, as it was also observed for the ITO-UQ and ITODPPC:UQ systems [21,22]. Fig. 7 presents the redox peak potentials of processes I and II vs. the scan rate for the ITO-MGDG:UQ 5:1 system and for the ITO-UQ system. The redox peak separation for both processes is enhanced when increasing the scan rate and similar behaviour is observed for process I of the ITO-MGDG:UQ 10:1 system (not shown). The redox peak separation for process II is larger than for process I indicating that process II is even more irreversible than process I. In addition, it can be also inferred from Fig. 7 that the increase in the scan rate affects in a larger extent the oxidation peak potential than the reduction one, which produces that the midpoint 
potential for process I and II has scan rate dependence. Moreover, the figure has been separated in low and high scan rates because at low scan rates $\left(<20 \mathrm{mV} \cdot \mathrm{s}^{-1}\right)$ the linear adjustments of the reduction and oxidation peak potentials of processes I and II present a higher slope (Fig. 7A and 7B) than at high scan rates (Fig. 7C).

This large separation for processes I and II has also been observed by other authors studying the electrochemical behaviour of surface confined $\cup Q$ at $\mathrm{pH}<12$ and it aroused from the slow values for the heterogeneous charge transfer rate constants [39, 43]. With the aim to perform an estimation of the charge transfer rate constant $\left(k_{a p p}\right)$ in the case of the ITO-MGDG:UQ/electrolyte interface, we have used the Laviron's formalism [38] applied to charge transfer eq. (1), considering that the reduction and oxidation peak potentials can be expressed by eq. (2) and (3), respectively:

$$
\begin{aligned}
& E_{p R}=E_{f}+\frac{R T}{\alpha_{a p p} n F} \ln \left(\frac{R T k_{a p p}}{\alpha_{a p p} n F v}\right)=E_{f}+m_{R} \ln \left(m_{R} k_{a p p}\right)-m_{R} \ln v \\
& E_{p O}=E_{f}-\frac{R T}{\left(1-\alpha_{a p p}\right) n F} \ln \left(\frac{R T k_{a p p}}{\left(1-\alpha_{a p p}\right) n F v}\right)=E_{f}-m_{O} \ln \left(m_{O} k_{a p p}\right)+m_{O} \ln v
\end{aligned}
$$

A representation of $\left(E_{p R}-E_{f}\right)$ and $\left(E_{p o}-E_{f}\right)$ vs. In $v$ (not shown) has been performed for the cathodic and anodic peak potentials of both electrochemical processes I, at each surface pressure, and II, at $\pi=33 \mathrm{mN} \cdot \mathrm{m}^{-1}$. The representations follow a good linearity. The apparent transfer coefficient $\alpha_{\text {app }}$ can be obtained from the slope $\left(m_{R}=R T /\left[\alpha_{a p p} n F\right]\right.$ and $\left.m_{\circ}=R T /\left[\left(1-\alpha_{a p p}\right) n F\right]\right)$ of the linear plots and the apparent charge transfer constants from the values of the intercept at the origin $\left(m_{R} \cdot \ln \left(m_{R} \cdot k_{a p p}\right)\right)$ and $\left(-m_{O} \cdot \ln \left(m_{\circ} \cdot k_{a p p}\right)\right)$. Different set of $\alpha_{\text {app }}$ and $k_{\text {app }}$ values have been obtained depending on the analysis of the cathodic (eq. 2) or anodic (eq. 3) peak potentials. For the cathodic peaks, the average values of $\alpha_{\text {Rapp }}(I)=0.48$ and $k_{\text {Rapp }}(I)=2.2 \cdot 10^{-5} \mathrm{~s}^{-1}$ are obtained for process $I$ and the values of $\alpha_{\text {Rapp }}(\mathrm{II})=0.63$ and $\mathrm{k}_{\text {Rapp }}(\mathrm{II})=5.1 \cdot 10^{-14} \mathrm{~s}^{-1}$ for process II. For the anodic peaks, the average values of $\alpha_{\text {Oapp }}(I)=0.80$ and $k_{\text {oapp }}(I)=3.3 \cdot 10^{-3} \mathrm{~s}^{-1}$ are obtained for process $\mathrm{I}$ and the values of $\alpha_{\text {Oapp }}(\mathrm{II})=0.75$ and $\mathrm{k}_{\text {Oapp }}(\mathrm{II})=6.1 \cdot 10^{-6} \mathrm{~s}^{-1}$ for process II. These results show that the reduction and oxidation processes of the UQ/UQH $\mathrm{H}_{2}$ redox couple confined in the lipid matrix have a different kinetic control at $\mathrm{pH} 7.4$, as it has been pointed by Marchal et al. [43] using the quantitative approach developed by Laviron [44-46]. According to the conclusions of Marchal et al. [43], in the 6-8 pH range, the rate determining step for the oxidation of the $\mathrm{UQ} / \mathrm{UQH}_{2}$ redox couple is the electron transfer process whereas for the reduction process at $\mathrm{pH}<7.5$ the rate determining step involves the protonation of UQ. Therefore, in our experimental system, we can consider that the apparent constants $\mathrm{K}_{\text {oapp }}(\mathrm{I})$ and $\mathrm{K}_{\mathrm{oapp}}(\mathrm{II})$ have the meaning of charge transfer constants whereas the apparent constants $k_{\text {Rapp }}(I)$ and $\mathrm{k}_{\text {Rapp }}(\mathrm{II})$ include the acid dissociation constant of the intermediate species. The values of $\mathrm{k}_{\mathrm{Oapp}}(\mathrm{I})$ are in the order of magnitude of the transfer charge rate constant reported by Marchal et al. [43]. The fact that the ratio $\mathrm{k}_{\mathrm{Rap}}(\mathrm{I}) / \mathrm{k}_{\mathrm{Rapp}}(\mathrm{II})$ was highest that the ratio $\mathrm{k}_{\mathrm{Oapp}}(\mathrm{I}) / \mathrm{k}_{\mathrm{Oapp}}$ (II) can be indicative of the different local environment around the UQ molecules that are reduced via process I or via process II. This causes changes in the apparent acid dissociation constant of the intermediate species involved in the reduction pathway. 
Figure 7. Peak potential vs. the scan rate for the (A) ITO-UQ and (B, C) ITOMGDG:UQ 5:1 systems transferred at several surface pressures. $(A, B)$ low scan rates

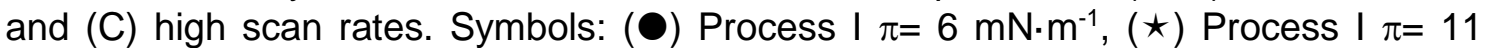
$\mathrm{mN} \cdot \mathrm{m}^{-1}$, (ઐ) Process II $\pi=11 \mathrm{mN} \cdot \mathrm{m}^{-1},(\boldsymbol{\Delta})$ Process I $\pi=15 \mathrm{mN} \cdot \mathrm{m}^{-1},(\boldsymbol{\square})$ Process I $\pi=$ $33 \mathrm{mN} \cdot \mathrm{m}^{-1},(\square)$ Process II $\pi=33 \mathrm{mN} \cdot \mathrm{m}^{-1}$. (Each data point represents a single scan).

The formal potential values for process I, $E_{\mathrm{f}}(\mathrm{I})$, obtained for the ITO-MGDG:UQ 5:1 and 10:1 systems (Table 2), are close to that obtained for process I in the ITO-UQ system [22] and therefore process I is correlated with the UQ molecules located in the lipid matrix with their heads in direct contact or in a short distance to the ITO surface. The most of the formal potentials observed by previous authors for the UQ redox processes confined on an electrode surface $[8,9,19,27,43,47-50]$ are in the range between $-0.14 \mathrm{~V}$ and $-0.09 \mathrm{~V}$ vs $\mathrm{Ag} / \mathrm{AgCl} / 3 \mathrm{M} \mathrm{KCl}$ at $\mathrm{pH} 7.4$. These last values are less thermodynamically favourable than that observed in this work for process I, which is correlated with the higher availability of protons in our system. On the other hand, the electrochemical process II has a formal potential, $E_{f}(\mathrm{II})$, more positive to that obtained for process I (Table 2) and close to the formal potential value obtained for process II in the ITO-UQ system [22]. The $E_{f}(\mathrm{II})$ value is also close to that of benzoquinone/hydroquinone in aqueous solution $\left(E_{f}(\mathrm{II}) \approx 0.14 \mathrm{~V} \mathrm{vs}\right.$. $\mathrm{Ag} / \mathrm{AgCl} / 3 \mathrm{M} \mathrm{KCl}$ [24] and it can be correlated with a more aqueous environment for the UQ headgroup. Therefore, we correlate process II with the redox behaviour of the UQ molecules that have been expelled from the MGDG matrix and are placed on top of the monolayer in an environment with higher $\mathrm{H}^{+}$ion availability from the aqueous electrolyte. The major irreversibility of process II compared with process I is correlated with the larger distance that the electron transfer is forced to proceed from the ITO surface to the UQ head, which induces a slowing of the overall electron-transfer rate as the obtained values of $k_{\text {app }}(\mathrm{I})$ and $\mathrm{k}_{\mathrm{app}}(\mathrm{II})$ shown. This behaviour has been also observed in SAMs of electro-active molecules $[41,50,51]$.

The charge involved in the LB monolayer transferred at each surface pressure is obtained by integrating the area under the reduction or oxidation waves. The surface coverage $(\Gamma)$ is obtained from the experimental values of charge and considering the global reaction (eq. 1) for $U Q$ in confined situation. The $\Gamma$ for the ITOMGDG:UQ/electrolyte system are shown in Table 3 and compared with the expected value to obtain the electroactive fraction of UQ. The expected surface coverage $\left(\Gamma_{\text {expec }}\right)$ values are calculated assuming that UQ and MGDG molecules are perfectly spread in a monolayer and on the ITO surface, being the resulting value corrected accordingly to the corresponding MGDG:UQ ratio and with the transfer ratio associated to the LB transfer process. We have chosen to show in Table 3 the oxidation surface coverage $\left(\Gamma_{0}\right)$ of the redox processes, which are similar but lower than the results obtained for the reduction scan due to the contribution of hydrogen evolution.

The Table 3 shows that an increase in the initial UQ content in ITOMGDG:UQ/electrolyte systems leads to an increase of the electroactive fraction. This fact is explained by the contribution of the electron hopping mechanism to the $\mathrm{UQ} / \mathrm{UQH}_{2}$ electron charge transfer, as it was also observed in the ITO-DPPC:UQ 
system [21]. Our results contrast with the observations of Moncelli et al. [47] who observed a decrease in the surface coverage when increasing the initial UQ content from 0.5 to $2 \%$ on a monolayer of DOPC on HDME at pH 9.5. This different behaviour is explained by the differences in $\mathrm{pH}$ values. Moncelli et al. [47] worked with $\mathrm{pH} 9.5$ so the availability of protons in the proximity of the UQ heads is more limited than in our experiments at $\mathrm{pH}$ 7.4. In our experiments the enough presence of available protons close to the UQ heads avoids the high local UQ concentration problem. On the other hand, $\Gamma_{O}(I)$ values (Table 3 ) are represented in Fig. 8 vs. the surface pressure. $\Gamma_{O}(I)$ for the ITO/MGDG:UQ 10:1 system attains a maximum value $\approx 10 \cdot 10^{-12} \mathrm{~mol} \cdot \mathrm{cm}^{-2}$, whereas $\Gamma_{O}(\mathrm{I})$ of the ITO/MGDG:UQ 5:1 system continues increasing.

Table 3. Expected $\left(\Gamma_{\text {expec }}\right)$, experimental total oxidation $\left(\Gamma_{O}\right.$ tot $)$ surface coverage, experimental surface coverage for process $\mathrm{I}, \Gamma_{O}(\mathrm{I})$, and electroactive fraction involved in the whole redox process for ITO-MGDG:UQ system using $0.150 \mathrm{M}$ of $\mathrm{KCl}$ electrochemical cell, with potassium phosphate buffered solution at $\mathrm{pH} 7.4$ and at a scan rate of $10 \mathrm{mV} \cdot \mathrm{s}^{-1}$.

Figure 8. Surface coverage of the $\mathrm{UQH}_{2}$ fraction oxidized via process $I, \Gamma_{O}(I)$, vs. surface pressure, $\pi$, for ITO-MGDG:UQ LB films with different MGDG:UQ content: (ם) 5:1 and (O) 10:1.

\subsection{Global sight of the MGDG:UQ system transferred on ITO}

A complete vision of the UQ positions in the MGDG:UQ monolayer can be obtained considering the monolayer physical states (Fig. 1), the AFM results reported in our previous work [31] and the electrochemical discussion presented in the previous section. The description of the UQ positons in the MGDG monolayer will be made using the model proposed by Söderhäll and Laaksonen [52]. They studied the position of UQ in a lipid bilayer through molecular dynamic studies, and concluded that UQ is in two preferred positions in the bilayer; one close to the lipid headgroups (diving position), the other in the membrane midplane (swimming position).

The different shape of the $C_{s}^{-1}$ curves and the lower $C_{s}^{-1}$ values observed for the MGDG:UQ mixtures compared to the pure MGDG (Fig. 1) indicate the presence of UQ molecules in the matrix of the MGDG:UQ mixtures (diving position) and it leads to less compact physical states. The shape of the $\pi-A$ isotherms, of the $C_{s}^{-1}$ curves and that of the first kink point in the $C_{s}^{-1}$ curves suggest that the system experiences a sudden UQ expulsion followed by a gradual expelling. The AFM studies of the LB films of pure MGDG and MGDG:UQ mixtures on mica reported in [31] indicated that the MGDG and the MGDG:UQ mixtures with low UQ content, both at low surface pressure, present similar covered area by the LC state, whereas the MGDG:UQ 5:1 ratio presents a markedly lower covered area by this LC state. These observations indicate that UQ is present in both physical states (LE and LC) in the MGDG:UQ mixtures. At $\pi$ $=6 \mathrm{mN} \cdot \mathrm{m}^{-1}$ the formal potential is $E_{f}(\mathrm{I})=-0.03 \pm 0.02 \mathrm{~V}$ for the ITO-MGDG:UQ 5:1 system and $E_{f}(\mathrm{I})=-0.07 \pm 0.02 \mathrm{~V}$ for the ITO-MGDG:UQ 10:1 system. Both are close to the formal potential of the redox process I obtained for the ITO-UQ/electrolyte system [22], which indicates that the local environment around each UQ is similar in 
these situations. However, the more negative value of the formal potential for the ITOMGDG:UQ 10:1 system may be related with the higher proportion of compact LC state compared with the pure UQ or the ITO-MGDG:UQ 5:1 system, which induces slight changes in the UQ environment that hindrances the electron transfer. Despite of these small differences, at low surface pressures, regardless the MGDG:UQ domains are in LE or LC state, we correlate the diving position with the UQ placed in the MGDG matrix and located in direct contact with the ITO surface (positon $I_{\alpha}$ at $\pi=6 \mathrm{mN} \cdot \mathrm{m}^{-1}$ in Schematic 1).

The compression of the monolayer, increasing the surface pressure, induces two actions: First the compactness of the LC state, so favouring the rejection of part of the UQ in diving position. On the one hand, it can be vertically rejected to a diving position without contact to the ITO surface (positon $\mathrm{I}_{\beta}$ at $\pi=15 \mathrm{mN} \cdot \mathrm{m}^{-1}$ in Schematic 1) and, on the other hand, horizontally to the remaining LE zones (Fig. 9B and $9 \mathrm{C}$ in reference [31]) so enriching them in UQ (some of the positons $I_{\alpha}$ at $\pi=15 \mathrm{mN} \cdot \mathrm{m}^{-1}$ and position $I_{\alpha}$ at $\pi=33 \mathrm{mN} \cdot \mathrm{m}^{-1}$ in Schematic 1 ). Second, the phase change from LE to LC of the remaining LE zones. Further compression results in a more compact LC state with very low proportion of covered areas by the LE state and the formation of filament shaped protrusions (Fig. 9D in reference [31]), which we relate with the presence of UQ molecules in swimming position forming pools on top of the monolayer (positon II at $\pi$ $=33 \mathrm{mN} \cdot \mathrm{m}^{-1}$ in Schematic 1). We correlate this swimming position with the process II observed in the CVs of Fig. 3 and 5, only for the ITO-MGDG:UQ 5:1 system. The process II for ITO-MGDG:UQ 10:1 is not observed, even at high scan rate.

The non-saturation of the $\Gamma_{O}$ (I) (Fig. 8) for ITO-MGDG:UQ 5:1 system when increasing the surface pressure at which the LB film has been transferred suggests that, when the monolayer changes from LE to LC, the horizontal rejection is favoured placing most of the UQ molecules in the diving position in LE zones, which become richer in UQ. In addition, the fast LE to LC change of the MGDG matrix entraps the UQ molecules in it, favouring the diving position versus the swimming position. The later position is only achieved at high initial UQ content and at high surface pressures due to the exceeding UQ molecules are rejected out of the MGDG matrix placing above the UQ molecules in diving position. The CVs (Fig. 3-5) show that process I presents wide redox peaks and express the redox behaviour of UQ molecules in diving position with their heads either in position $I_{\alpha}$ or $I_{\beta}$ (Schematic 1). Comparing with the ITO-DPPC:UQ system [22], the slower phase change from LE to LC of the DPPC matrix, when increasing the surface pressure, favoured the progressive vertical rejection of the UQ molecules, and thus two separated electrochemical processes were observed for the diving UQ molecules, directly or not directly in contact with the ITO surface (labelled as processes I and I', respectively [22]). The slower phase change for the DPPC:UQ system also leads to a saturation of the $\Gamma_{O}(I)$ value, in contrast with what has been observed for the MGDG:UQ 5:1 system.

Schematic 1. Scheme of the position of MGDG and UQ molecules of the MGDG:UQ $5: 1$ system at several surface pressures. The labels $I_{\alpha}, I_{\beta}$ and II indicate the UQ positions that origin the redox processes I and II. 


\section{Conclusions}

The electrochemical response of the MGDG:UQ monolayer on ITO depends on the surface pressure at which it has been transferred and on the MGDG:UQ ratio. At low surface pressures and low UQ content, only one irreversible redox process (I) is obtained. At high surface pressures and high UQ content an additional redox process (II) is obtained. Process II is more irreversible than process I but has a more positive formal potential. At $\mathrm{pH} 7.4$, either for processes I and II, the rate determining step for the reduction of the $\mathrm{UQ} / \mathrm{UQH}_{2}$ redox couple involves the protonation of UQ molecules whereas the oxidation is kinetically controlled by the electron transfer rate. The positions of the UQ molecules in the MGDG matrix have been determined analysing the formal potential values of both redox processes, and the compactness and physical states of the monolayer at each surface pressure and composition. The diving position with UQ molecules in direct contact with the ITO surface is the main position at low surface pressures and low UQ content. Increasing the surface pressure, the fast compactness of the MGDG matrix produces vertical rejection of the UQ molecules, which leads to a diving position without direct contact of the UQ heads with the ITO surface, and it also produces horizontal rejection of the UQ molecules to remaining LE zones. The electron transfer reaction of all the UQ molecules in diving position proceeds via the redox process I, indicating that in all the described situations the UQ heads are in a close distance respect to the ITO surface. At high surface pressures and high UQ content, the higher compactness of the MGDG matrix leads to the expulsion of UQ molecules to the top of the monolayer, giving the swimming position. The electron transfer reaction of the molecules in swimming position proceeds via the redox process II. The major irreversibility of process II compared with process I is correlated with the larger distance that the electron transfer is forced to proceed from the ITO electrode to the UQ head, which induces a slowing of the overall electron-transfer rate. The LB technique allows to build biomimetic membranes with control, through the surface pressure, of the UQ position and, consequently, of the redox process.

\section{Acknowledgements}

The authors thank the economic support of the Spanish Government, through the project CTQ2007-68101-C02, and of the Catalonia Autonomic Government, through the project SGR2009-277. J Hoyo thanks to Universitat Politècnica de Catalunya its PhD grant. 


\section{References}

[1] E. Swiezewska, G. Dallner, B. Andersson, L. Ernster, Biosynthesis of ubiquinone and plastoquinone in the endoplasmic reticulum-Golgi membranes of spinach leaves, J. Biol. Chem. 268 (1993) 1494-1499.

[2] M. Jemiola-Rzeminska, J. Kruk, M. Skowronek, K. Strzalka, Location of ubiquinone homologues in liposome membranes studied by fluorescence anisotropy of diphenylhexatriene and trimethylammonium-diphenyl-hexatriene, Chem. Phys. of Lipids, 79 (1996) 55-63.

[3] R. Jono, K. Yamashita, Two Different Lifetimes of Charge Separated States: a Porphyrin-Quinone System in Artificial Photosynthesis J. Phys. Chem. C 116 (2012) 1445-1449.

[4] T. Nagata, Y. Kikuzawa, An approach towards artificial quinone pools by use of photo- and redox-active dendritic molecules, Biochim. Biophys. Acta 1767 (2007) 648652.

[5] D. Gust, T.A. Moore, A.L. Moore, Solar Fuels via Artificial Photosynthesis, Acc. Chem. Res. 42 (2009) 1890-1898.

[6] A. Nelson, Electrochemistry of mercury supported phospholipid monolayers and bilayers, Current Opinions in Colloid and Interface Science, 15 (2010) 455-466.

[7] M.R. Moncelli, L. Becucci, A. Nelson, R. Guidelli, Electrochemical modeling of electron and proton transfer to ubiquinone-10 in a self-assembled phospholipid monolayer, Biophys. J. 70 (1996) 2716-2726.

[8] L. Becucci, F. Scaletti, R. Guidelli, Gel-phase microdomains and lipid rafts in monolayers affect the redox properties of ubiquinone-10, Biophys. J. 101 (2011) 134143.

[9] G. J. Gordillo, D. J. Schiffrin, Redox properties of ubiquinon (UQ10) adsorbed on a mercury electrode, J. Chem. Soc. Faraday Trans. 90 (1994) 1913-1922.

[10] G. J. Gordillo, D. J. Schiffrin, The electrochemistry of ubiquinone-10 in a phospholipid model membrane, Faraday Discuss. 116 (2000) 89-107.

[11] R. Guidelli, G. Aloisi, L. Becucci, A. Dolfi, M. R. Moncelli, F. T. Buoninsegni, New directions and challenges in electrochemistry. Bioelectrochemistry at metal/water interfaces, J. Electroanal. Chem. 504 (2001) 1-28.

[12] J. Yang, M. Kleijn, Order in phospholipid Langmuir-Blodgett layers and the effect of the electrical potential of the substrate, Biophysical J. 76 (1999) 323-332.

[13] J. Kruk, K. Strzalka, R-M. Leblanc, Linear dichroism and molecular orientation in Langmuir-Blodgett films of plastoquinones and alpha-tocopherol quinone, Biochem. Biophys. Acta 1142 (1993) 6-10.

[14] Z. V. Leonenko, E. Finot, H. Ma, T.E. S. Dahms, T. Cramb, Investigation of Temperature-Induced Phase Transitions in DOPC and DPPC Phospholipid Bilayers Using Temperature-Controlled Scanning Force Microscopy, Biophys. J. 86 (2004) 3783-3793.

[15] J. Lipkowski, Building biomimetic membrane at a gold electrode surface, Phys. Chem. Chem. Phys. 12 (2010) 13874-13887.

[16] J. T. Woodward, C. W. Meuse, Mechanism of formation of vesicle fused phospholipid monolayers on alkanethiol self-assembled monolayer supports, J. Colloid Interface Sci. 334 (2009) 139-145. 
[17] T. A. Oleson, N. Sahai, Interaction energies between oxide surfaces and multiple phosphatidylcholine bilayers from extended DLVO-theory, J. Colloid Interface Sci. 352 (2010) 316-326.

[18] M. Anderson, J. Jackman, D. Wilson, P. Jarvoll, V. Alfredson, G. Okeyo, R. Duran, Vesicle and bilayer formation of diphytanoylphosphatidylcholine (DPhPC) and diphytanoylphosphatidylethanolamine (DPhPE) mixtures and their bilayers' electrical stability, Colloids and Surf. B: Biointerfaces 82 (2011) 550-561.

[19] J-M. Laval, M. Madja, Electrochemical investigations of the structure and electron transfer properties of phospholipid bilayers incorporating ubiquinone, Thin Solid Films 244 (1994) 836-840.

[20] E. Torchout, C. Bourdillon, J-M. Laval, Reconstitution of functional electron transfer between membrane biological elements in a two-dimensional lipidic structure at the electrode interface, Biosensors and Bioelectronics 9 (1994) 719-723.

[21] J. Hoyo, E. Guaus, G. Oncins, J. Torrent-Burgués, F. Sanz, Incorporation of ubiquinone in supported lipid bilayers on ITO, J. Phys. Chem. B 117 (2013) 7497-7506.

[22] J. Hoyo, E. Guaus, J. Torrent-Burgués, F. Sanz, Electrochemical behaviour of mixed LB films of ubiquinone - DPPC. J. Electroanal. Chem. 669 (2012) 6-13.

[23] S. Sanchez, A. Arratia, R. Córdova, H. Gómez, R. Schrebber, Electron transport in biological processes. Electrochemical behavior of Q10 immersed in a phopholipidic matrix added on a pyrolitic graphite electrode, Bioelectrochemistry and Bioenergetics 36 (1995) 67-71.

[24] H. Park, J-S. Park, Y-B. Shim, Redox reaction of benzoquinone on a lipid coated glassy carbon electrode, J. Electroanal. Chem. 438 (1997) 113-119.

[25] H. Shiba, K. Maeda, N. Ichieda, M. Kasuno, Y. Yoshida, O. Shirai, S. Kihara, Voltammetric study on the electron transport through a bilayer lipidmembrane containing neutral or ionic redox molecules, J. Electroanal. Chem. 556 (2003) 1-11.

[26] E. Torchout, J-M Laval, C. Bourdillon, M. Madja, Electrochemical measurements of the lateral diffusion of electroactive amphiphiles in supported phospholipid monolayers, Biophys. J. 66 (1994) 753-762.

[27] D. Marchal, W. Boireau, J. M. Laval, J. Moiroux, C. Bourdillon, An electrochemical approach of the redox behavior of water insoluble ubiquinones or plastoquinones incorporated in supported phospholipid layers, Biophys. J. 72 (1997) 2679-2687.

[28] D. Marchal, W. Boireau, J. M. Laval, J. Moiroux, C. Bourdillon, Electrochemical measurement of lateral diffusion coefficients of ubiquinones and plastoquinones of various isoprenoid chain lengths incorporated in model bilayers, Biophys. J. 74 (1998) 1937-1948.

[29] V. Mirceski; R. Gulaboski, I. Bogeski, M. Hoth, Redox chemistry of Ca-transporter 2-palmitoylhydroquinone in an artificial thin organic film membrane, J. Phys. Chem. 111 (2007) 6068-6076.

[30] P. J. Quinn, M. A. Esfahani, Ubiquinones have surface-active properties suited to trans-port electrons and protons across membranes, Biochem. J. 185 (1980) 715-722.

[31] J. Hoyo, E. Guaus, J. Torrent-Burgués, Biomimetic monolayer films of monogalactosyldiacylglycerol incorporating ubiquinone, J. Colloid Interface Sci. 384 (2012) 189 - 197.

[32] G. Cevc, D. Marsh, Phospholipid Bilayers. Physical Principles and Models, WileyInterscience, New York, 1987. 
[33] J. Yang, J. M. Kleijn, Order in Phospholipid Langmuir-Blodgett Layers and the Effect of the Electrical Potential of the Electrical Potential of the Substrate, Biophys. J. 76 (1999) 323-332

[34] G. Wiegand, N. Arribas-Layton, H. Hillebrandt, E. Sackmann, P. Wagner, Electrical Properties of Supported Lipid Bilayer Membranes, J. Phys. Chem. B 106 (2002) 42454254.

[35] G. Aloisi, L. Becucci, A. Dolfi, M.R. Moncelli, F. Tadini-Buoninsegni, R. Guidelli, Interfacial bioelectrochemistry: assessment and trends, J. Electroanal. Chem. 504 (2001) 1-28.

[36] S.A. Petrova, M.V. Kolodyazhny, O.S. Ksenzhek, Electrochemical properties of some naturally occurring quinones, J. Electroanal. Chem. 277 (1990) 189-196.

[37] A.J. Bard, L.R. Faulkner, Electrochemical Methods. Fundamentals and Applications, John Wiley\& Sons, New York, 2001.

[38] E. Laviron, General expression of the linear potential sweep voltammogram in the case of diffusionless electrochemical systems, J. Electroanal. Chem. 1979, 101, 19-28.

[39] C. Mårtensson, V. Agmo Hernández, Ubiquinone-10 in gold-immobilized lipid membrane structures acts as a sensor for acetylcholine and other tetraalkylammonium cations, Bioelectrochemistry 88 (2012) 171-80.

[40] Y. Li, L. Shi, W. Ma, D.W. Li, H.B. Kraatz, Y.T. Long, 6-Vinyl coenzyme Q0: Electropolymerization and electrocatalysis of NADH oxidation exploiting poly-pquinone-modified electrode surfaces, Bioelectrochemistry 80 (2011) 128-131.

[41] H.G. Hong, W. Park, Electrochemical characteristics of hydroquinone-terminated self-assembled monolayers on gold, Langmuir 17 (2001) 2485-2492.

[42] R. Bilewicz, S. Sek, I. Zawisza, Electron transport through composite monolayers. Russ. J. Electrochem. 38 (2002) 29-38.

[43] D. Marchal, W. Boireau, J.M. Laval, C. Bourdillon, J. Moiroux, Kinetics of redox conversion at a gold electrode of water-insoluble ubiquinone (UQ(10)) and plastoquinone $(\mathrm{PQ}(9))$ incorporated in supported phospholipid layers, J. Electroanal. Chem. 451 (1998) 139-144.

[44] E. Laviron, Electrochemical reactions with protonations at equilibrium: Part VII. The $2 \mathrm{e}, 1 \mathrm{H}^{+}$reaction (six-member fence scheme) for a surface or for a heterogeneous reaction in the absence of disproportionation or dimerization, J. Electroanal. Chem. 146 (1983) 1-13.

[45] E. Laviron, Electrochemical reactions with protonations at equilibrium: Part VIII. The $2 \mathrm{e}, 2 \mathrm{H}^{+}$reaction (nine-member square scheme) for a surface or for a heterogeneous reaction in the absence of disproportionation and dimerization reactions, J. Electroanal. Chem. 146 (1983) 15-36.

[46] E. Laviron, Electrochemical reactions with protonations at equilibrium: Part X. The kinetics of the $p$-benzoquinone/hydroquinone couple on a platinum electrode, $\mathrm{J}$. Electroanal. Chem. 164 (1984) 213-227.

[47] M.R. Moncelli, R. Herrero, L. Becucci, R. Guidelli, Kinetics of electron and proton transfer to ubiquinone-10 and from ubiquinol-10 in a self-assembled phosphatidylcholine monolayer, Biochim. Biophys. Acta. 1364 (1998) 373-384.

[48] L.J.C. Jeuken, R.J.D. Bushby, S.D. Evans, Proton transport into a tethered bilayer lipid membrane, Electrochemistry Communications 9 (2007) 610-614. 
[49] W. Ma, Y.L. Ying, L.X. Qin, Z. Gu, H. Zhou, D.W. Li, T.C. Sutherland, H.Y. Chen, Y.T. Long, Investigating electron-transfer processes using a biomimetic hybrid bilayer membrane system, Nat. Protoc. 3 (2013) 439-450.

[50] W. Ma, D-W. Li, T.C. Sutherland, Y. Li, Y-T. Long, H-Y. Chen, Reversible Redox of $\mathrm{NADH}$ and NAD+ at a Hybrid Lipid Bilayer Membrane Using Ubiquinone, J. Am. Chem. Soc. 133 (2011) 12366-12369.

[51] H. Gao, G.A. Luo, J. Feng, A.L. Ottova, H.T. Tien, Fabrication and photoelectric properties of self-assembled bilayer lipid membranes on conducting glass, $\mathrm{J}$. Photochem. Photobiol. B 59 (2000) 87-91.

[52] J. A. Söderhäll, A. Laaksonen, Molecular Dynamics Simulations of Ubiquinone inside a Lipd Bilayer, J. Phys. Chem. B 105 (2001) 9308-9315. 


\section{Captions for figures}

Figure 1. Surface pressure-area isotherms and inverse of the compressibility modulus vs. surface pressure (inset) for the films: (A) MGDG, (B) MGDG:UQ 10:1, (C) MGDG:UQ 5:1 and (D) UQ.

Figure 2. Cyclic voltammograms at $v=10 \mathrm{mV} \cdot \mathrm{s}^{-1}$ of the systems: (A) ITO/electrolyte, (B) ITO-MGDG/electrolyte at $\pi=33 \mathrm{mN} \cdot \mathrm{m}^{-1}$ and (C) ITO-MGDG/electrolyte at $\pi=6$ $\mathrm{mN} \cdot \mathrm{m}^{-1}$. All CVs have been performed in a $0.150 \mathrm{M} \mathrm{KCl}$ solution buffered at $\mathrm{pH} 7.4$. Inset: $C_{d}$ of the $(A)$ and $(B)$ systems obtained from the CVs.

Figure 3. Cyclic voltammograms at $v=10 \mathrm{mV} \cdot \mathrm{s}^{-1}$ of the (A) ITO-MGDG LB film transferred at $\pi=33 \mathrm{mN} \cdot \mathrm{m}^{-1}$ and of the (B, C, D) ITO-MGDG:UQ 5:1 LB films transferred at several surface pressures: (B) $\pi=6 \mathrm{mN} \cdot \mathrm{m}^{-1},(C) \pi=15 \mathrm{mN} \cdot \mathrm{m}^{-1}$ and (D) $\pi=33 \mathrm{mN} \cdot \mathrm{m}^{-1}$. Inset: $\mathrm{CV}$ of the system (D) in a shorter potential working screen. All $\mathrm{CVs}$ have been performed in a $0.150 \mathrm{M} \mathrm{KCl}$ solution buffered at $\mathrm{pH}$ 7.4.

Figure 4. Cyclic voltammograms at $v=10 \mathrm{mV} \cdot \mathrm{s}^{-1}$ of the (A) ITO-MGDG LB film transferred at $\pi=33 \mathrm{mN} \cdot \mathrm{m}^{-1}$ and of the (B, C, D) ITO-MGDG:UQ 10:1 LB films transferred at several surface pressures: (B) $\pi=6 \mathrm{mN} \cdot \mathrm{m}^{-1},(C) \pi=15 \mathrm{mN} \cdot \mathrm{m}^{-1}$ and (D) $\pi=33 \mathrm{mN} \cdot \mathrm{m}^{-1}$. All CVs have been performed in a $0.150 \mathrm{M} \mathrm{KCl}$ solution buffered at $\mathrm{pH}$ 7.4 .

Figure 5. Cyclic voltammograms at $v=200 \mathrm{mV} \cdot \mathrm{s}^{-1}$ of the ITO-MGDG:UQ LB films transferred at $\pi=33 \mathrm{mN} \cdot \mathrm{m}^{-1}$ with different MGDG:UQ content: (A) 10:1 and (B) 5:1. Inset: CVs of the systems (A) and (B) and CV of the (C) ITO-UQ LB film transferred at $\Pi=11 \mathrm{mN} \cdot \mathrm{m}^{-1}$, in a shorter potential working screen and scanned at $v=10 \mathrm{mV} \cdot \mathrm{s}^{-1}$. All $\mathrm{CVs}$ have been performed in a $0.150 \mathrm{M} \mathrm{KCl}$ solution buffered at $\mathrm{pH} 7.4$.

Figure 6. Oxidation peak current vs. the scan rate for the ITO-MGDG:UQ 5:1 system transferred at several surface pressures. Symbols: $(\mathbf{0})$ Process I $\pi=6 \mathrm{mN} \cdot \mathrm{m}^{-1},(\mathbf{\Delta})$ Process I $\pi=15 \mathrm{mN} \cdot \mathrm{m}^{-1}$, ( $\left.\boldsymbol{\square}\right)$ Process $\mathrm{I} \pi=33 \mathrm{mN} \cdot \mathrm{m}^{-1}$ and $(\square)$ Process $\| \pi=33$ $\mathrm{mN} \cdot \mathrm{m}^{-1}$. (Each data point represents a single scan).

Figure 7. Peak potential vs. the scan rate for the (A) ITO-UQ and (B, C) ITOMGDG:UQ 5:1 systems transferred at several surface pressures. $(A, B)$ low scan rates and (C) high scan rates. Symbols: (O) Process I $\pi=6 \mathrm{mN} \cdot \mathrm{m}^{-1},(\star)$ Process I $\pi=11$ $\mathrm{mN} \cdot \mathrm{m}^{-1}$, (k) Process II $\pi=11 \mathrm{mN} \cdot \mathrm{m}^{-1},(\boldsymbol{\Delta})$ Process I $\pi=15 \mathrm{mN} \cdot \mathrm{m}^{-1}$, (苂) Process I $\pi=$ $33 \mathrm{mN} \cdot \mathrm{m}^{-1},(\square)$ Process II $\pi=33 \mathrm{mN} \cdot \mathrm{m}^{-1}$. (Each data point represents a single scan).

Figure 8. Surface coverage of the $\mathrm{UQH}_{2}$ fraction oxidized via process $I, \Gamma_{O}(\mathrm{I})$, vs. surface pressure, $\pi$, for ITO-MGDG:UQ LB films with different MGDG:UQ content: (ם) 5:1 and (O) 10:1.

Schematic 1. Scheme of the position of MGDG and UQ molecules of the MGDG:UQ 5:1 system at several surface pressures. The labels $I_{\alpha}, I_{\beta}$ and II indicate the UQ positions that origin the redox processes I and II. 


\section{Curriculum Vitae}

Javier Hoyo is graduated in chemical engineering (2007) and chemistry (2012) at the University of Barcelona. Postgraduate formation consists on a MSC in Molecular Biotechnology (2009) and a MSC in Chemical Process Engineering (2010) and he obtained his PhD in 2014 from the Universitat Politècnica de Catalunya (UPC). He has international working experience, staying in 2006-2007 in the Technische Universität Berlin and national, working in the Catalonia Bioengineering Institute (IBEC). He is currently member of the LEIPN laboratory at the UPC where studies the preparation of biomimetic membranes that are suitable for artificial photosynthesis.

Ester Guaus Guerrero graduated in chemistry in 1986 and obtained his PhD in 1993. She is associated professor in the Department of Chemical Engineering of the Universitat Politècnica de Catalunya (UPC) and is member of the CRNE (research centre of nanoengineering). She has been working in the research fields of: electrochemical interfaces, single metal and alloy electrodeposition, modified electrodes and electroactive thin films. She is currently involved in the study of the redox properties of organized and biomimetic thin films. She is also member of the Electrochemistry Group of the Real Spanish Society of Chemistry.

Juan Torrent-Burgués graduated in chemistry in 1983 and obtained his $\mathrm{PhD}$ in 1988, at the University of Barcelona. He is Full Professor and teaches chemistry, optical materials and coatings, and nanotechnology in the Department of Chemical Engineering of the Universitat Politècnica de Catalunya (UPC). Visiting investigator at the University of Utrecht (1990) and at the Scientific Park of Barcelona (2003-04), his research fields are electrochemistry, interphases, materials and organized thin films, such as Langmuir and LB films, and their nanomechanical or redox properties. He is member of the CRNE of the UPC and researcher associate to the IBEC.

Fausto Sanz graduated in chemistry in 1971 and obtained his PhD in 1975 from the University of Barcelona (UB). He is Full Professor and currently teaches in the Department of Physical Chemistry, UB, in the fields of surface science, electrochemistry and SPM applications. Visiting investigator at the University of Utrecht (1985-86) and Visiting Scholar at the Lawrence Berkeley Laboratory (University of California) (1991-92), his research started in electrochemistry and progressively developed to include surface science using nanoprobes. He is currently involved in biointerphases projects, having joined the IBEC. He is an active member of the Northern California Chapter of the AVS and of the Electrochemical Society. 
Table 1. Values of collapse surface pressure $\left(\pi_{c}\right)$, area of lift-off $\left(A_{l_{0}}\right)$, surface pressure at the main UQ expulsion ( $\left.\pi_{\mathrm{m} \cup \mathrm{Q}}\right)$, area at the main UQ expulsion ( $\mathrm{A}_{\mathrm{m} \cup \mathrm{Q}}$ ), maximum value of the inverse of compressibility before physical state change $\left(C_{s}^{-1} \max b\right)$, maximum value of the inverse of compressibility after physical state change $\left(C_{s}^{-1} \max a\right)$, and monolayer physical state (PS).

\begin{tabular}{|llllllll|}
\hline & $\begin{array}{l}\pi_{\mathrm{c}} \\
(\mathrm{mN} / \mathrm{m})\end{array}$ & $\begin{array}{l}\mathrm{A}_{\mathrm{lo}} \\
\left(\AA^{2} / \mathrm{molec}\right)\end{array}$ & $\begin{array}{l}\pi_{\mathrm{mUQe}} \\
(\mathrm{mN} / \mathrm{m})\end{array}$ & $\begin{array}{l}\mathrm{A}_{\mathrm{mUQe}} \\
\left(\AA^{2} / \mathrm{molec}\right)\end{array}$ & $\begin{array}{l}\mathrm{C}_{\mathrm{s}}^{-1} \mathrm{max} \text { b } \\
(\mathrm{mN} / \mathrm{m})\end{array}$ & $\begin{array}{l}\mathrm{C}_{\mathrm{s}}^{-1} \mathrm{max} \mathrm{a} \\
(\mathrm{mN} / \mathrm{m})\end{array}$ & PS \\
MGDG & 53 & 59 & - & - & 200 & 320 & LC-S \\
MGDG:UQ 10:1 & 52 & 65 & 14.3 & 53.1 & 100 & 220 & LE-LC \\
MGDG:UQ 5:1 & 53 & 72 & 13.4 & 55.1 & 70 & 200 & LE-LC \\
UQ & 11 & 102 & - & - & 30 & & LE \\
\hline
\end{tabular}


Table 2. Redox peaks potentials for processes I and II and the formal potential that they represent for the ITO-MGDG:UQ 5:1 and 10:1 systems.

\begin{tabular}{|clccccc|}
\hline$\pi\left(\mathrm{mN} \cdot \mathrm{m}^{-1}\right)$ & $E_{p R}(\mathrm{I})(\mathrm{V})$ & $E_{p O}(\mathrm{I})(\mathrm{V})$ & $E_{f}(\mathrm{I})(\mathrm{V})$ & $E_{p R}(\mathrm{II})(\mathrm{V})$ & $E_{p O}(\mathrm{II})(\mathrm{V})$ & $E_{f}(\mathrm{II})(\mathrm{V})$ \\
\hline & & \multicolumn{7}{c|}{ ITO-MGDG:UQ 5:1 } & \\
6 & $-0.25 \pm 0.02$ & $0.16 \pm 0.02$ & $-0.04 \pm 0.02$ & - & - & - \\
15 & $-0.27 \pm 0.02$ & $0.24 \pm 0.02$ & $-0.02 \pm 0.02$ & - & $0.62 \pm 0.03$ & - \\
33 & $-0.34 \pm 0.02$ & $0.28 \pm 0.02$ & $-0.03 \pm 0.02$ & $-0.54 \pm 0.01$ & $0.65 \pm 0.02$ & $0.06 \pm 0.03$ \\
& & & ITO-MGDG:UQ 10:1 & & - \\
6 & $-0.28 \pm 0.02$ & $0.12 \pm 0.02$ & $-0.08 \pm 0.02$ & - & - & - \\
15 & $-0.31 \pm 0.02$ & $0.18 \pm 0.03$ & $-0.07 \pm 0.03$ & - & - & - \\
33 & $-0.33 \pm 0.02$ & $0.22 \pm 0.02$ & $-0.06 \pm 0.02$ & - & - & - \\
\hline
\end{tabular}


Table 3. Expected $\left(\Gamma_{\text {expec }}\right)$, experimental total oxidation $\left(\Gamma_{O}\right.$ tot $)$ surface coverage, experimental surface coverage for process I, $\Gamma_{O}(\mathrm{I})$, and electroactive fraction involved in the whole redox process for ITO-MGDG:UQ system using $0.150 \mathrm{M}$ of $\mathrm{KCl}$ electrochemical cell, with potassium phosphate buffered solution at $\mathrm{pH} 7.4$ and at a scan rate of $10 \mathrm{mV} \cdot \mathrm{s}^{-1}$.

\begin{tabular}{|ccccc|}
\hline $\begin{array}{c}\pi \\
\left(\mathrm{mN} \cdot \mathrm{m}^{-1}\right)\end{array}$ & $\begin{array}{c}\Gamma_{\text {expec }}\left(10^{-12} \mathrm{~mol} \cdot\right. \\
\left.\mathrm{cm}^{-2}\right)\end{array}$ & $\begin{array}{c}\Gamma_{\text {O tot }}\left(10^{-12} \mathrm{~mol} \cdot\right. \\
\left.\mathrm{cm}^{-2}\right)\end{array}$ & $\begin{array}{c}\Gamma_{O}(\mathrm{I})\left(10^{-12} \mathrm{~mol}\right. \\
\left.\mathrm{cm}^{-2}\right)\end{array}$ & $\begin{array}{c}\text { Electroactive } \\
\text { ITO-MGDG:UQ } 5: 1\end{array}$ \\
6 & 19.0 & 10.4 & 10.4 & 54.9 \\
15 & 41.5 & 21.4 & 15.8 & 51.6 \\
33 & 50.3 & 47.7 & 32.8 & 94.7 \\
& & ITO-MGDG:UQ 10:1 & \\
6 & 14.2 & 4.4 & 4.4 & 31.0 \\
15 & 24.7 & 9.9 & 9.9 & 40.1 \\
33 & 28.2 & 11.8 & 11.8 & 41.8 \\
\hline
\end{tabular}


Figure 1

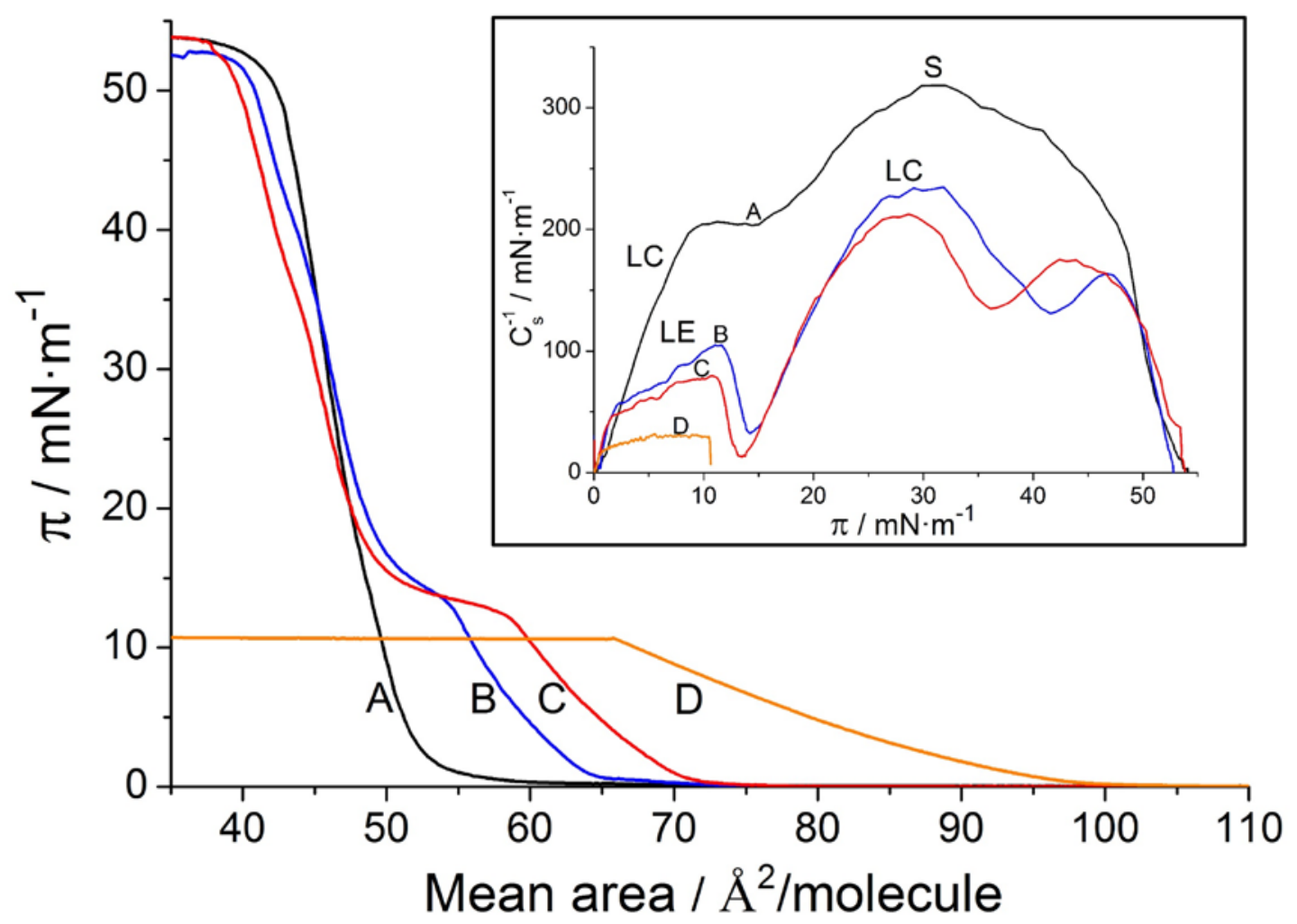


Figure 2

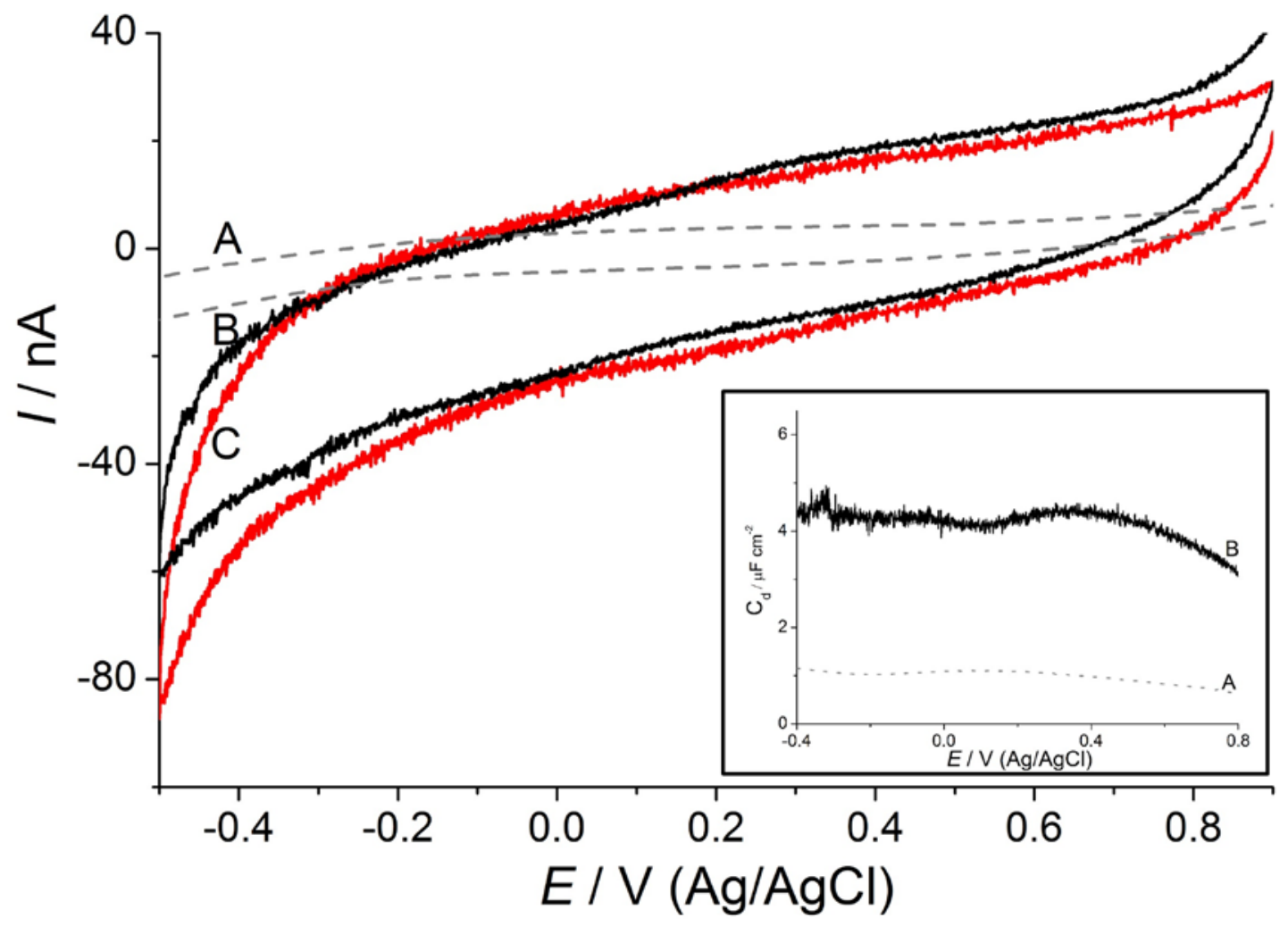


Figure 3

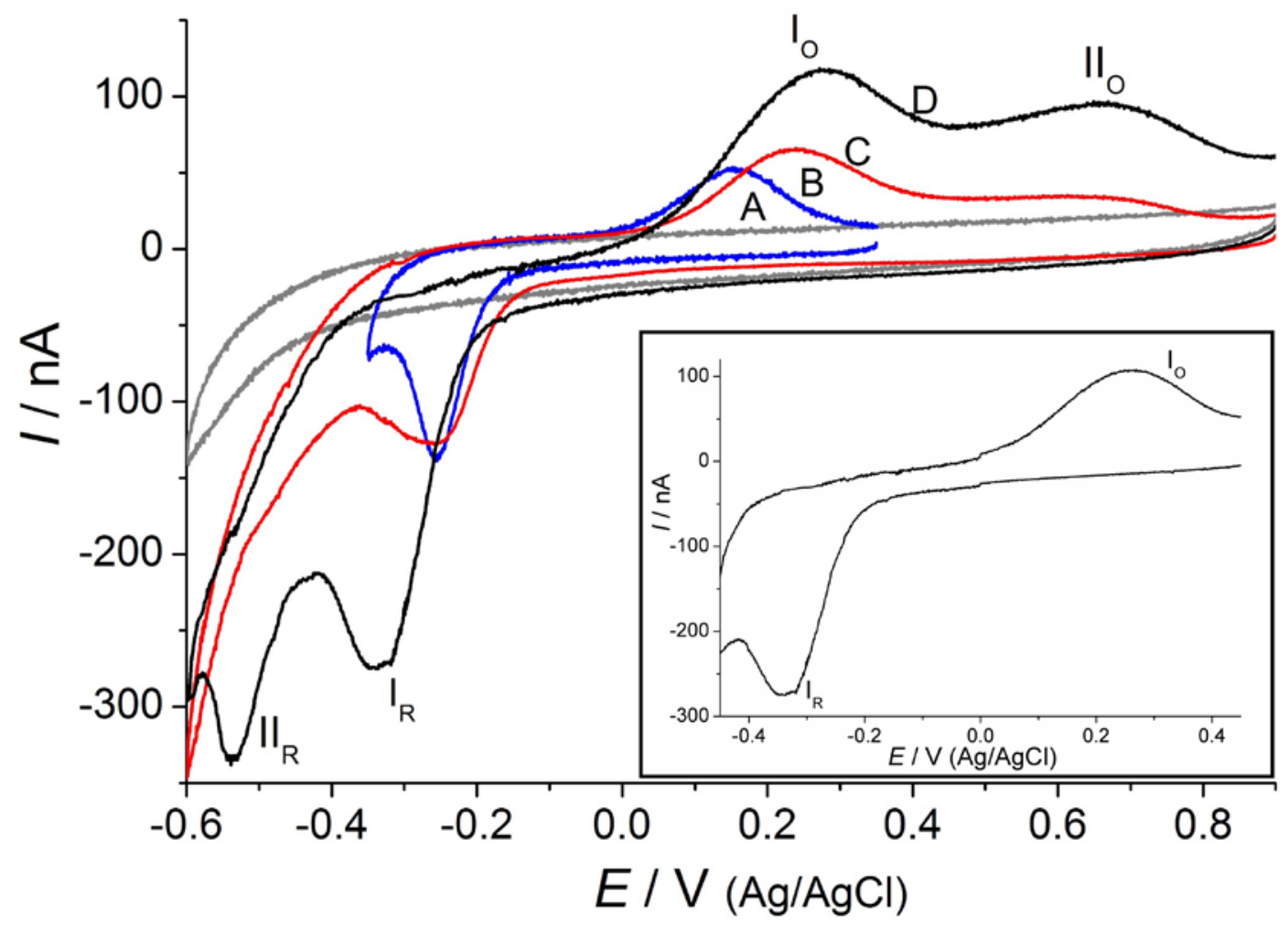


Figure 4

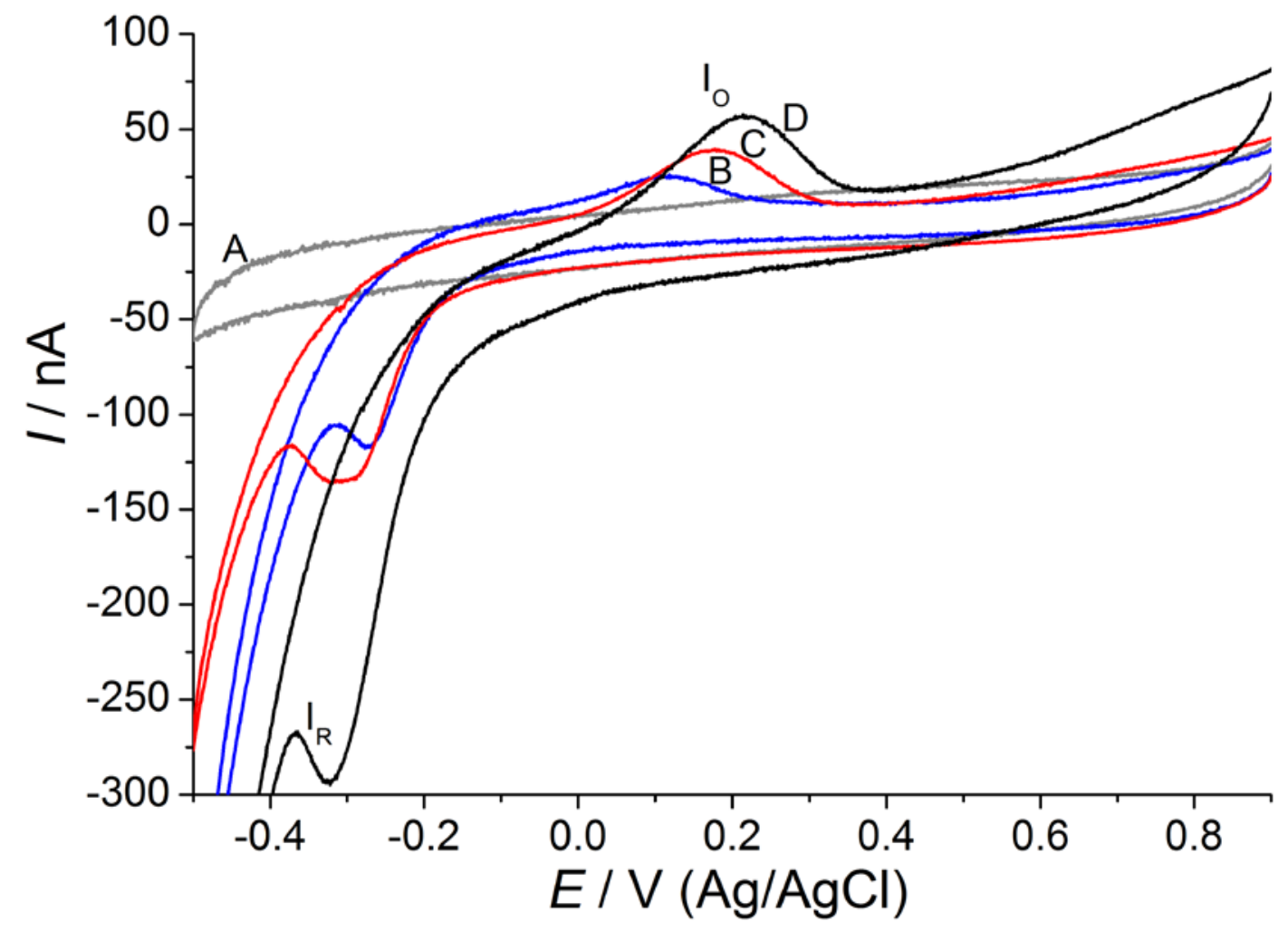


Figure 5

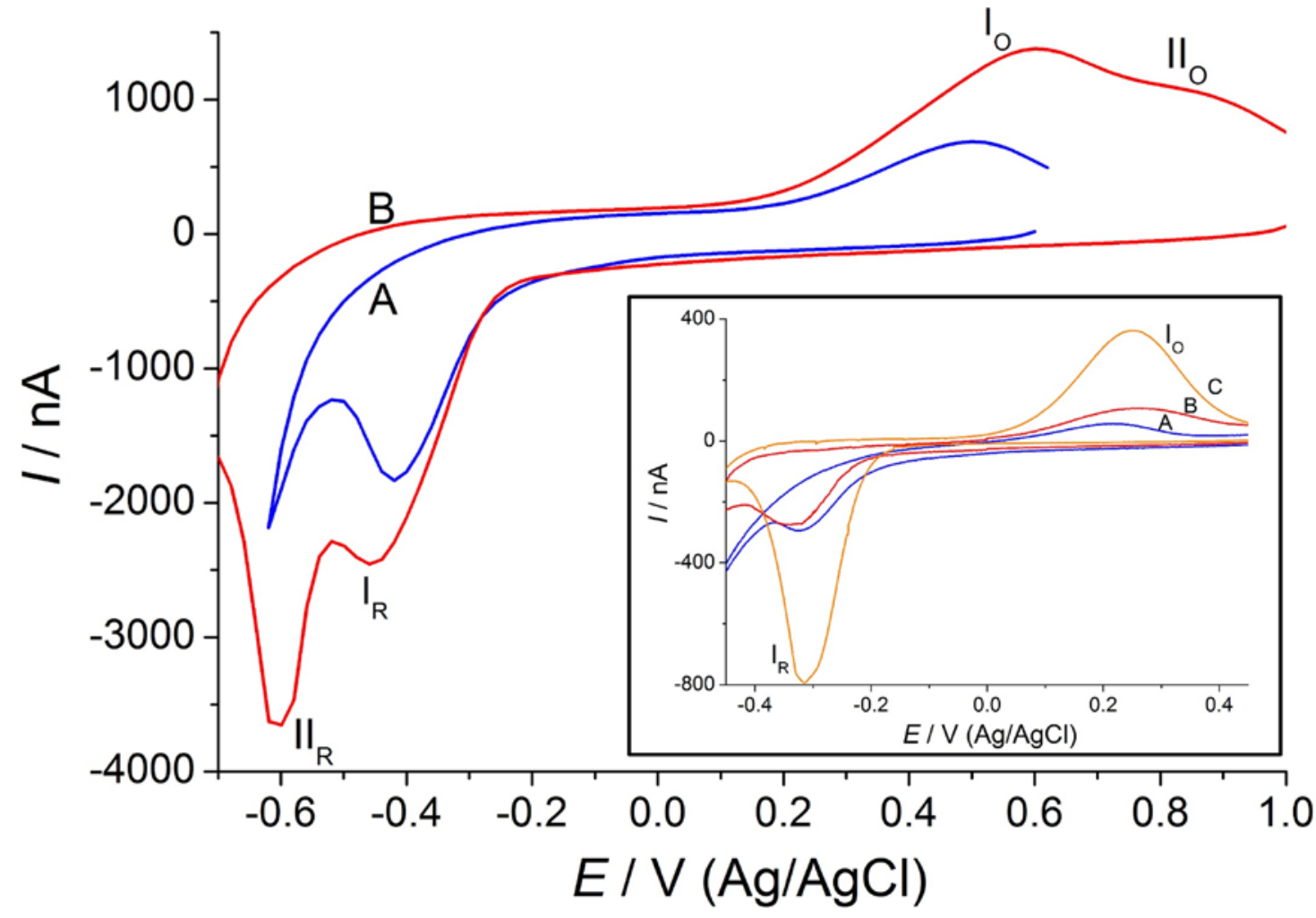


Figure 6

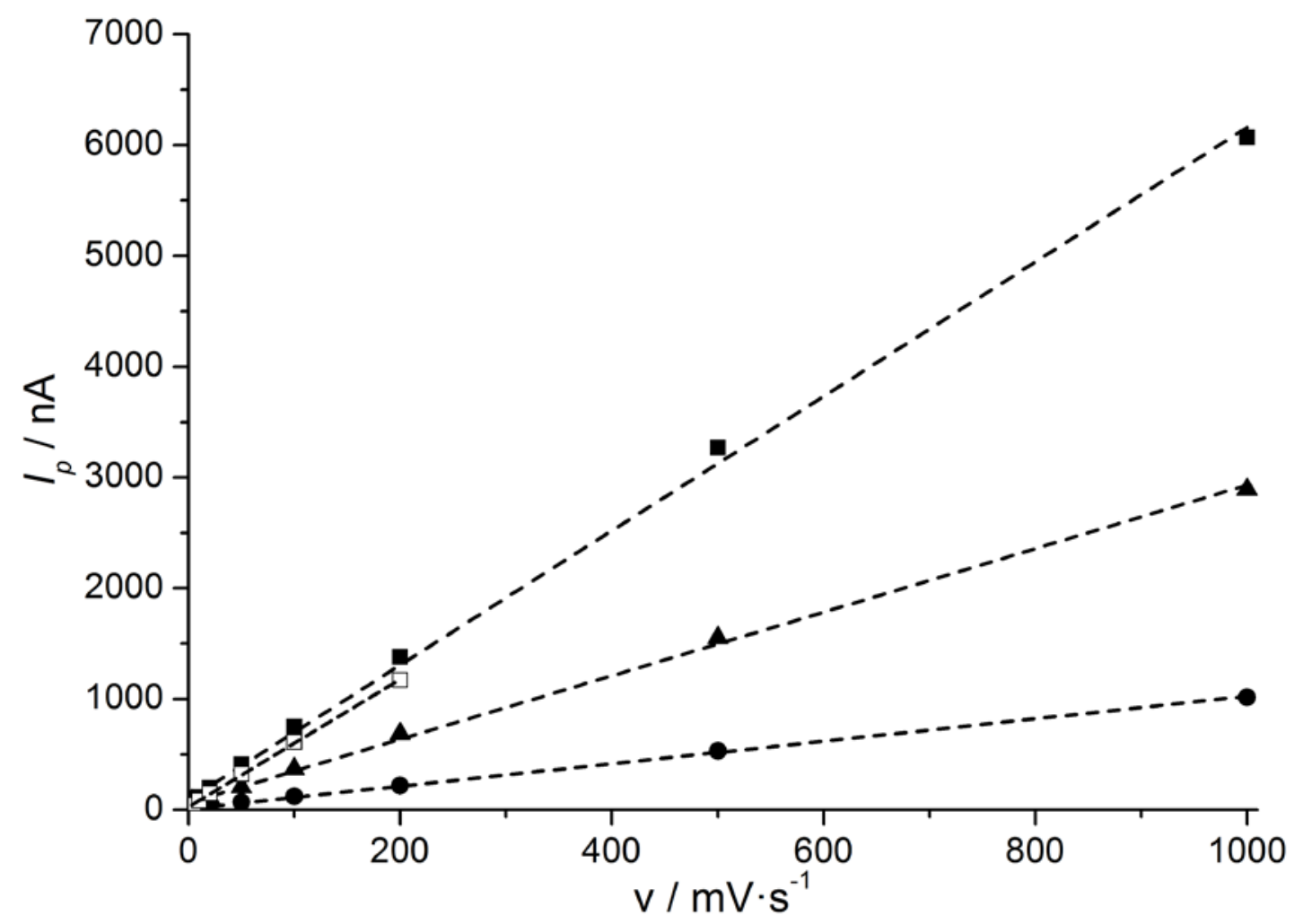


Figure 7
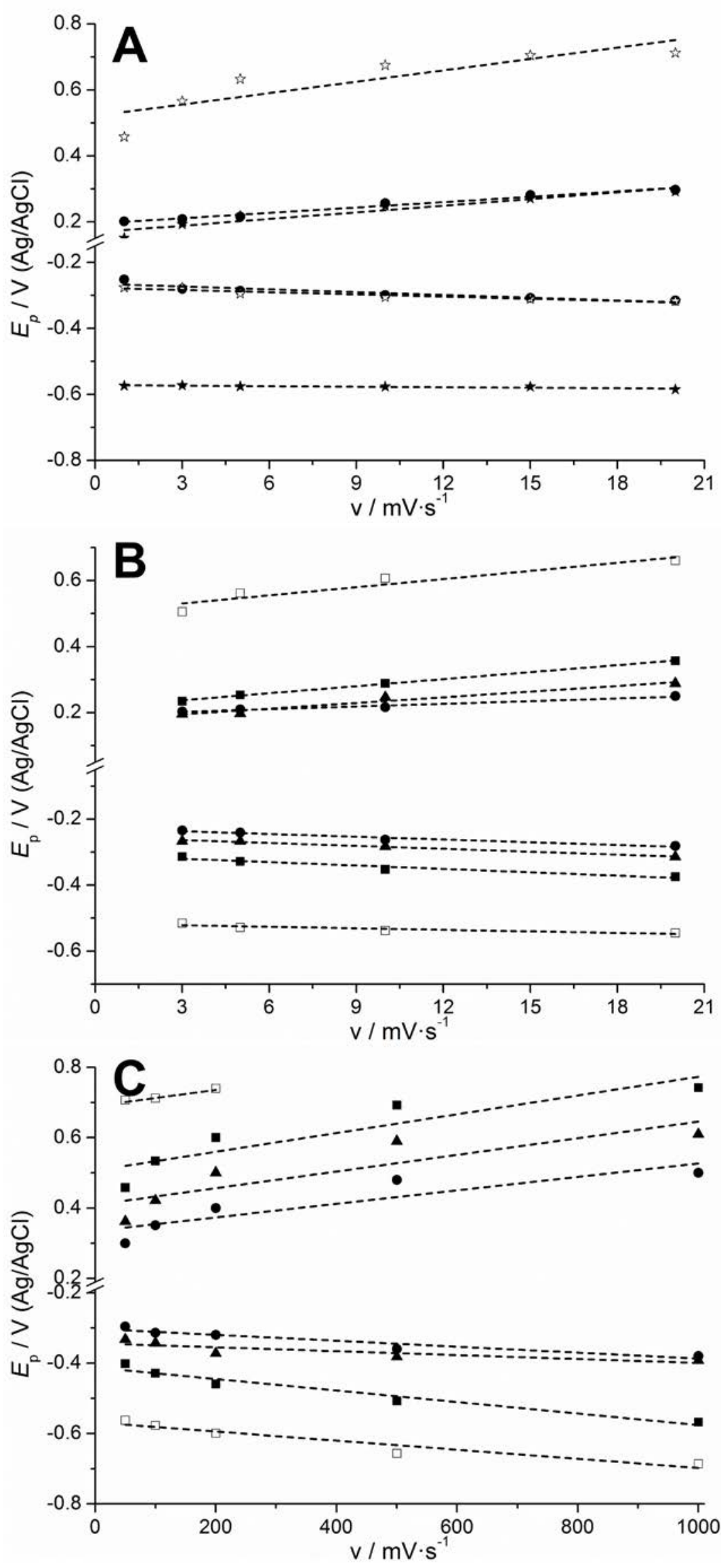
Figure 8

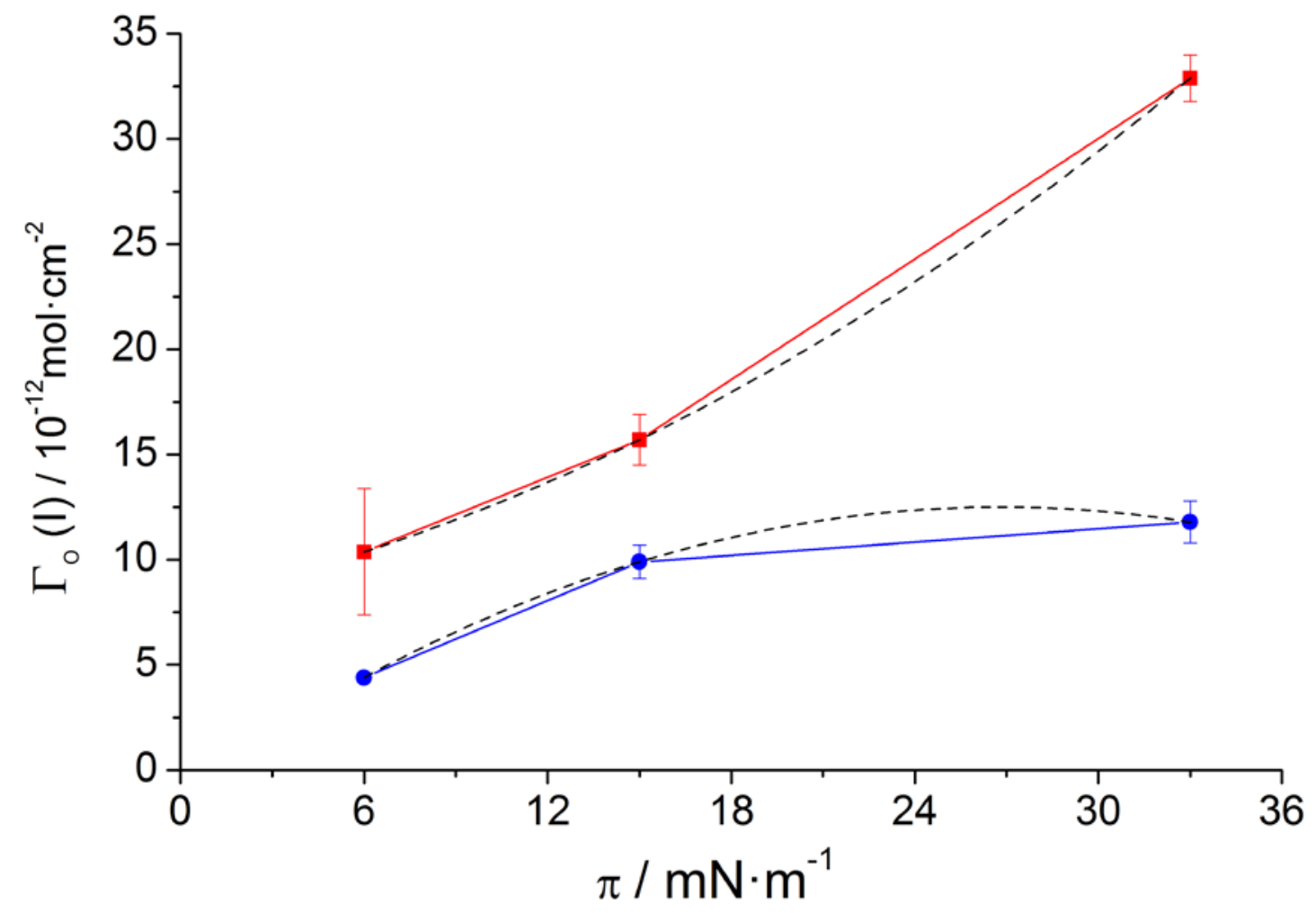


Schematic 1

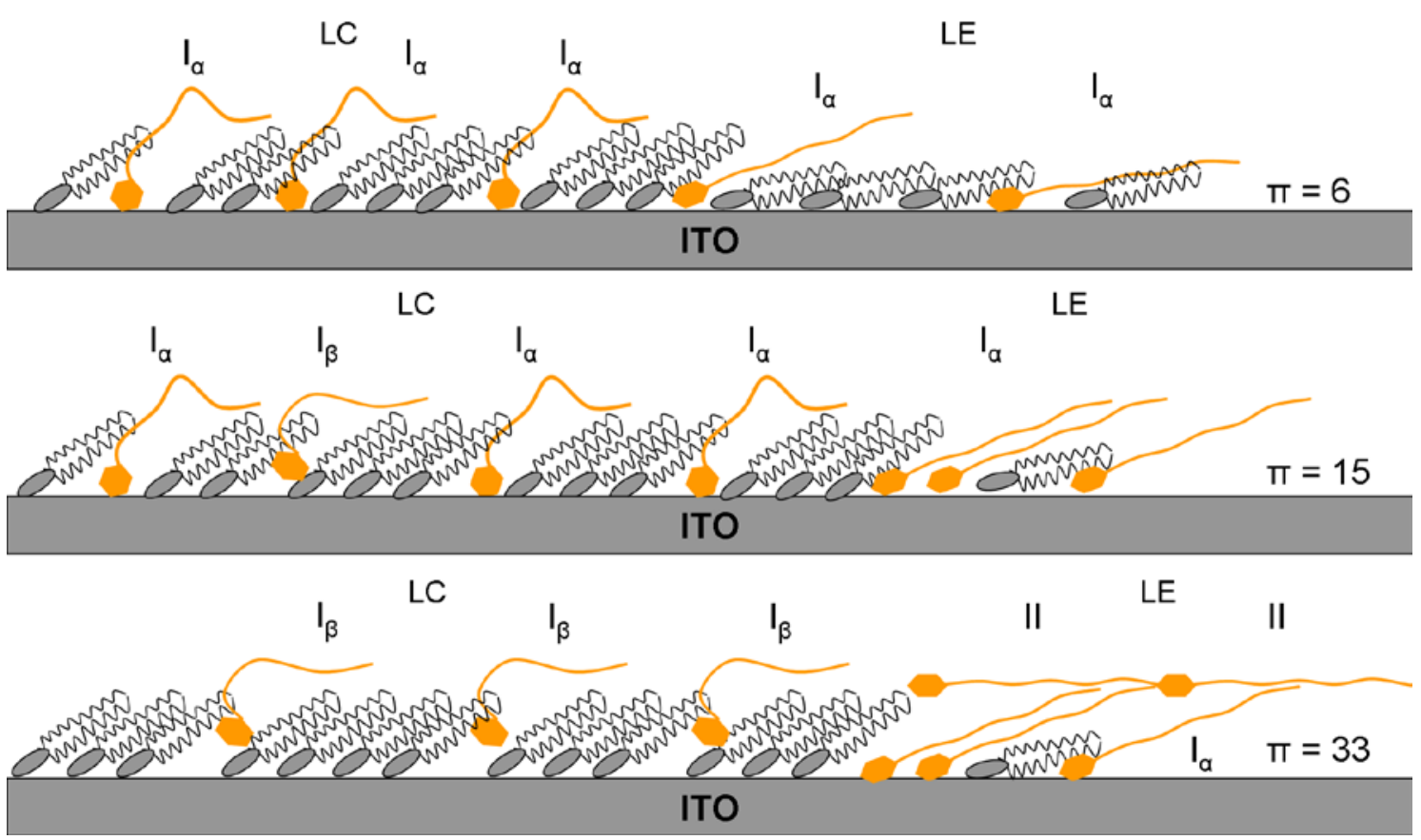

